\title{
3DTV Mass Adoption in the United States and The National FoOtball LEAGUE
}

\author{
Marian Ehret \\ Stamford International University, Thailand \\ marian.ehret@stamford.edu
}

\begin{abstract}
The purpose was to examine how mass adoption of 3DTV in the United States as the next major step in TV evolution could occur after the technology recently failed in the 2010s. Answers to the research questions focused on understanding what conditions for mass adoptions would need to exist and how the National Football League TV transmissions could support the adoption process until when. An integrated literature review defined inhibiting factors to adoption, related to technology, health, content, marketing strategy, and price. Solution paths were proposed. Rogers' diffusion of innovation theory and the Bass model were applied in a comparatist perspective, comparing 3DTV to historical adoption patterns of HDTV and colour TV. The comparatist approach proved to be very useful, as forecast models ignoring historical adoption patterns usually failed. Findings revealed that most American households could possess 3DTV sets by 2032 if Avatar sequels would kick off another cycle of 3D cinema, followed by a 3DTV re-introduction.
\end{abstract}

Keywords: 3DTV, mass adoption, National Football League, HDTV, new media

\section{INTRODUCTION}

The researcher aimed at understanding how and until when the annual National Football League (NFL) season could contribute to mass adoption of 3DTV in the United States: featuring with its annual championship game, the Super Bowl, America's most important sports event. The purpose of the study was also to understand the impact of the Avatar sequels on 3DTV mass adoption, providing solutions to eliminate adoption inhibiting factors and applying a comparatist perspective to related technology such as HDTV. FutureSource predicted in 2011 wrongly that $60 \%$ of US households would have a 3DTV set by 2015 (Paul, 2016). 3DTV was declared dead as early as 2013 (Mehrabov, 2015). In 2016, the world's largest TV maker Samsung reported that 3D would not be part of its future TV plans (Katzmeier, 2017). In 2017, both Sony and LG declared that they would not offer any 3DTV support anymore (Leswing, 2017). It seemed that 3DTV had failed. But 3D was also considered a 
cyclical technology, undergoing phases of popularity and the lack thereof. 3D cinema was launched in the mid-1950s, returned in the 1960s (Carey \& Elton, 2010).

3DTV had its premiere in 1982 with an episode of the UK science magazine, The Real World (Wiki, 2012). In the 1990s, the IMAX system brought 3D back to the big screen (Mehrabov, 2015). In 2009, James Cameron's Avatar, one of the most successful movies ever made, sparked another return of 3D back to cinema and the ill-fated, latest appearance on TV (Napoli, 2018). Because of its cyclical nature, some researchers believed in another potential comeback of 3DTV (Napoli, 2018). If this would happen and reach the mainstream of US society, it would follow adoption patterns of older consumer media that initially failed, but were successfully adopted over time and later classified as having had a "false start," like FM Radio (Carey \& Elton, 2010). The researcher wanted to answer the following questions: How could the National Football League contribute to kick off a successful mass adoption of 3DTV in the United States and until when? What conditions must be given to support 3DTV mass adoption in America? The answers to these questions mattered commercially to manufacturers of TV technology focusing on the consumer market. The mass adoption of 3DTV by $50 \%$ of the American population would, in terms of technicality and significance, be comparative to previous major steps in the evolution of TV, the introduction of colour TV and HDTV (Obrist, Wurhofer, Meneweger, Grill \& Tscheligi, 2013). A major point of concern was that of the 30,000 consumer products introduced each year newly, more than $90 \%$ failed (Elton \& Carey, 2010), including new media products such as 3DTV.

Moreover, Elton and Carey (2010) were unaware of any specific new media marketing forecasts projecting failure. In other words: while new media forecasts indicated a failure rate of $0 \%$, the real failure rate was above $90 \%$. The failure to account for failure had strong negative implications for product manufacturers: hindering rational planning when dealing with a situation of uncertainty (Elton \& Carey, 2010). There was an urgent need for applying a more sophisticated forecast model to project the market introduction of new media products in general and of a product as impactful as 3DTV in particular (Elton \& Carey, 2010). The Bass model was a forecast model developed in response to the shortcomings of older forecast models (Elton \& Carey, 2010), but it was never applied to a 3DTV development projection in an integrated approach. Scholars criticized in addition that past 3DTV studies focused too much on technical aspects and neglected the factor of user experience, which essentially decided on whether a technology would be adopted or not. They had called for more research, addressing this research gap (Obrist et al., 2013). An integrated, but not entirely comprehensive, literature review addressing the inhibiting factors of technology, consumer health, need for content, marketing strategy, and the product price was conducted, touching both technical and sociological aspects and their interactions.

A media archaeologist and comparatist perspective generated findings by focusing on the related cases of colour TV and HDTV and applying them to the National Football League in the context of 3DTV mass adoption. The Bass model, perceived as the most sophisticated model forecasting the demand for new products, was for the first time applied in an integrated approach, specifying precise kick-off moments for diffusion, to explain the temporal diffusion patterns for a successful 3DTV rollout in the United States (Carey \& Elton, 2010). A clear definition of inhibiting factors was necessary as a pre-condition for applying the Bass model in an integrated approach. 


\section{CONTEXT AND BACKGROUND OF STUDY}

As sports content to be examined as suitable for the mass adoption of 3DTV, the TV transmissions of the National Football League (NFL) had been picked. Football was seen as an archetypical American sport. It was perceived as an aggressive game, which used violence and technology to achieve an individual economic advantage, thereby fitting to American ideology (Wenner, 1989). The Super Bowl, the NFL's annual championship game, achieved 114 million viewers in 2015, representing more than one-third of the entire US population (Nielsen, 2017), being America's most important sports event. One NFL contract with the broadcasters Fox, CBS, and ABC/ESPN lasted from 1997 until 2005 and was worth USD17.8 billion (Wasko, 2009). The story of the NFL began in 1920, when the American Professional Football Association was founded in Canton, Ohio. In 1922, the name was changed to the National Football League (Carroll, 2020). When black and white TV was rolled out on the American market from 1947 until 1955, NFL matches were popular. Americans who could not afford their own TV set went to local bars or to their neighbours' homes to follow the NFL sports matches (Carey \& Elton, 2010).

The NFL in the 1960s faced a serious rival: the American Football League (AFL). In 1966, both Leagues merged (Carroll, 2020). The merger included the agreement to organize an end-of-season championship match: the AFL-NFL World Championship Game. This game was played for the first time on 15 January 1967, between the Green Bay Packers and the Kansas City Chiefs (Carroll, 2020). This match was one of the first examples of regular colour TV broadcasting - and it would help CBS establish itself when colour TV was young (Koonce, 2012). This game would be remembered as the first Super Bowl, even if that name would appear in 1969 only. The Super Bowl would become America's most popular sports TV event (Carroll, 2020). ABC launched in 1970 even a regular series during the football season, Monday Night Football (Britannica, 2020). The NFL games were a big draw for HDTV as well. Sports events with physical movements and bright colours appeared well in wider HDTV images and higher resolution (Carey \& Elton, 2010).

CBS broadcasted already in the late 1990s four NFL matches in HD (Lechner, 1999). 22\% of all HDTV set purchases took place because the buyers wanted to watch the Super Bowl (Poor Audiophile, 2013). Because of that, some were even willing to pay USD33,000 for a 70inch HDTV set from Sony, and HDTV set sales regularly peaked before annual Super Bowl events. (Macedonia, 2007). HDTV represented for the NFL a huge marketing opportunity. But it also convinced potential viewers to stay at home instead of exposing themselves to all the hassle related to entering a stadium (Sanderson \& Siegfried, 2018), enjoying options such as replays in ultra-slow motion.

\section{INTEGRATED LITERATURE REVIEW ON INHIBITING ADOPTION FACTORS}

Many 3DTV sets were at introduction before 2016 too dim even if it would have been possible to create TV sets with stronger lamps (Silva, 2019). In 2015, Dolby Laboratories, headquartered in San Francisco, California, USA, introduced HDR TV set displays with high dynamic range (Pilot Navigating Broadcasting's Future, 2020). HDR displays would have improved the light output capability of 3DTV sets, but no 3DTV sets with HDR displays were designed (Silva, 2019). Also, no 3DTV sets in 4K resolution existed in 2016, which further diminished the possible viewer experience (Silva, 2019). Many technical formats used standards that 
were incompatible with the ones of other manufacturers, like 3D glasses of company $\mathrm{X}$ being incompatible with the 3D glasses of company $\mathrm{Y}$. These technical factors hindered the successful adoption of 3DTV in the 2010s (Silva, 2019). For creating 3DTV sports events, as in National Football League matches, the big 3DTV cameras would need to be moved closer to the playing field, where the visually attractive action happens (Carey \& Elton, 2010). 3D images should give the spectator a feeling of being co-present. This effect could be achieved if the images would be recorded from a low camera angle. However, this would require no unwanted objects to cover essential movements (Postley, 2012).

While a loss of 2D packets in video streaming would to some extent be considered tolerable, 3D packets must be transmitted entirely if the viewing experience should not be seriously disturbed. Enough TV broadcast channels would have to be provided for all NFL 3DTV events, as the broadcast transmission required the use of 2 channels at the same time for one 3DTV transmission process (Kim \& Jeon, 2016). In comparison, only one channel at a time would be needed for a 2DTV event transmission. Positive is the technical possibility of compressing 3D video content significantly (Baaren, Van de Wijngaert, \& Huizer, 2011). Binaural audio was found to expand the 3D impression beyond the visual impact. Binaural audio and related sensory effects contributed to creating an immersive environment when watching and listening to sports events and action films (Luque, Galloso, Feijoo, Martín, \& Cisneros, 2014). A small percentage of the human population was due to physiological reasons perceived as unable to experience the effect of 3D images. Another third of the global population was supposed to have only a limited perception of depths (Vatolin, 2011).

Associated with 3DTV were essential health effects. Some viewers complained about nausea and brain fatigue as a result of 3DTV consumption. 3DTV was perceived as especially harmful to teenagers (Chen, Wang, Lu, Liu, \& Chen, 2018). The effect of sickness could be mitigated by improving technical aspects of colour match, alignment, and focus between the two different lenses of a 3DTV camera. Recording less nausea-causing images without compromising the entertainment aspect of fast, dynamic movements could also help (Postley, 2012). Stereoscopic broadcasting, with its prerequisite of requiring the use of 3D glasses, was perceived by many scholars as one of the reasons for adverse health effects (Kellnhofer et al., 2017), more affecting older and female than younger and male viewers. Moreover, stereoscopic devices were even considered as the leading cause for the commercial failure of the 2010s (Mehrabov, 2015).

A big problem when introducing a new media technology was the availability of content. In 2014, only 22 3D channels were reported worldwide, broadcasting to a major extent content in 3D (LyngSat, 2014). In comparison, 14,000 TV channels were available in 2014 worldwide (Gunkel, 2014). What sense did it make to buy a 3DTV set when not enough content was being broadcast in 3D? The amount of available 3DTV content should enormously be increased to pave a breakthrough for 3DTV. An NFL-related example shall indicate the need. In September 2010, only a pre-season game between two teams was broadcast in 3D in the American northeast. Most of the NFL matches would need to be available in 3D nationwide to offer useful content choices for this kind of sports (Shanbhag, 2010). On a much more fundamental level, the demand for 3D content required to define production criteria.

Not all content produced in 3D was equally appealing as in 2D. Content should be visually attractive, dynamic, possessing a lot of movements and action, providing the spectator with simulated presence and an immersive experience (Carey \& Elton, 2010). When 3DTV sets 
were introduced on a large scale in the 2010s, many manufacturers had insufficient marketing strategies. Many manufacturers overlooked the fact that 3DTV sets followed too soon on a recent major shift from analogue to digital TV devices. Customers were unwilling to make a significant investment that soon again (Silva, 2019). Also, many store sales representatives did not correctly communicate the functions of a 3DTV set. That was an even more significant shortcoming, as the success of 3D technology depended on demonstrations (Wolf, 2010). The 3D online streaming offers, or the 3D Blu-ray player, demanded additional investments, overwhelming potential customers financially (Silva, 2019). Institutions must think of better marketing strategies when introducing 3DTV sets to households (Baaren et al., 2011).

\section{DTV in the Eyes of Everett Rogers' Diffusion of Innovation Model}

Because of its scope and depth was the work of sociologist Everett Rogers on the diffusion of innovation supported by a large number of scholars (Rogers, 1995). It was applied in the context of this study and in a comparatist perspective used with colour TV, HDTV, and 3DTV to generate findings related to the case of NFL TV transmissions. Rogers focused not only on how individuals and organizations adopted new technology. He also focused on the complexities involved, the time that the rollout took, how adopters experienced different forms of exposure to the technology, the required behaviours to be learned, and the different sociodemographic qualities of divergent groups of adopters (Rogers, 1995).

Rogers understood that technology could change its qualities over time, what mattered to the study of 3DTV. He introduced the idea of a benchmark to be reached to define a new technology's success. When a product was adopted by more than $50 \%$ of a market's population, mass adoption had successfully taken place (Rogers, 1995). He defined five categories of adopters: innovators, early adopters, early majority, late majority, and laggards. Innovators were a small group, comfortable with taking risks. Early adopters were also a small group of opinion leaders with an extensive network of followers, usually possessing higher income means. The two groups of major significance for this study are the early and the late majority. As the names already indicated represented both of these the two largest groups (Rogers, 1995). At the switch of adoption from early to the late majority, the breakthrough happened.

The critical benchmark of reaching more than half of the entire market's population would be achieved. Members of the early majority were people following early adopters and their opinions after some time. The late majority was characterized by scepticism and caution, only adopting when sufficiently motivated due to social pressure or financial reasons. Laggards were traditional people, often of limited financial means (Rogers, 1995). Rogers' model was still recently in wide use. It was applied for a study of factors influencing the adoption of sustainable practices in the tourism industry (Dibra, 2015). In combination with Geert Hofstede's typology of culture, was it used to study the diffusion of virtual social networks across different countries (Krishnan \& Lymm, 2016). Rogers' theory provided a useful framework to study the diffusion of digital innovation in poetry (Fleming-May \& Green, 2016). Finally were psychological constructs of his theory used to study the adoption of renewable heating systems (Franceschinis et al., 2017).

\section{The 3DTV Mass Adoption and Frank Bass' Model}

Frank Bass designed one of the most advanced forecast models for new products. His model was also used for this study and in a comparatist perspective applied to colour TV, HDTV, 
and 3DTV to arrive at findings in the context of NFL TV transmissions. Bass differed between external and internal influence, affecting a potential customer's purchase decisions. The first one could be manifest in the form of the mass media, the latter through interpersonal word of mouth within an adopter's social network (Bass, 1969). During the adoption process, the first half of the adoption phase was perceived as the most significant one for internal and external communication channels. The internal influence was regarded as the much more effective one, describing an S-curve with a high peak in the first half of the diffusion process (Bass, 1969).

Further adoption would, in the second half of the diffusion process, for both external and internal communication channels develop linear, respectively, almost linear (Bass, 1969). The nearly linear adoption due to internal influence would happen after the S-curve levelled down. In the case of internal influence, the adoption would then even result in a slight decrease, but still at an overall higher level than for the external communication channel (Bass, 1969). Other scholars supported the generalized variant of Bass' model when comparing it to other approaches, even without including decision variables (Bass, Krishnan, \& Jain, 1994). Bass' model was applied to the diffusion of new products in social networks in general and to forecast product sales in the automotive industry (Fan, Che, \& Chen, 2017). In its generalized form, his model was again used to understand wind power development in China (She, Cao, Xie, Ma, \& Lan, 2019).

\section{Research Method and Limitations}

The purpose of this study was to understand under which conditions and until when a potential 3DTV re-introduction on the American market could achieve a mass adoption rate of $50 \%$. This study used a comparatist, qualitative textual analysis approach: applying Everett Rogers diffusion of innovation model and Frank Bass' model. Both models were useful to understand the quantitative impact, and temporal scope of diffusion (Rogers, 1995): and whether the impact would be achieved due to external or internal influence (Bass, 1969). Both models could be applied in combination with each other (Carey \& Elton, 2010). Rogers himself supported Bass' model, as he perceived it as aligned with his theory (Carey \& Elton, 2010). Especially the Bass model was useful in avoiding the shortcomings of older forecast models (Carey \& Elton, 2010). NFL TV transmissions and Avatar sequels were analyzed as potential major factors facilitating the diffusion process (Busch, 2020; Chang et al., 2014). The temporal diffusion patterns of 3DTV were based on comparisons with the historical diffusion patterns of HDTV (Grenier-Hemphill, 2015) and colour TV to arrive at more reliable results (Carey \& Elton, 2010). As useful as Bass' model was, it did experience its shortcomings. First of all, internal and external influences were required to be noncumulative, what in reality could not be guaranteed (Bass, 1969). Secondly, the nature of the product and the consumer behaviour needed to be stable. In times, where product innovations happened often and consumers were subject to fashion trends, this was not always likely. Finally needed Bass' model a longitudinal research design for long-term observation to produce reliable results: including the time period in which the early adoption process would describe the peak of the S-curve (Bass, 1969). As mentioned above was the value of Bass' model despite some shortcomings still recognized today (Bass et al., 1994; Fan et al., 2017; She et al., 2019).

As this study generally employed textual analysis approach, it may have experienced some limitations in addition to the ones described. It was based on secondary data, including its rights and wrongs. Observation results could be validated by adding the collection of 
primary data as an additional layer of verification. The study of 3DTV mass adoption could also be continued in a longitudinal research design, enabling long-term observation. The focus on the United States and the NFL would limit results to a North American context, even if this market is of huge importance. Specific adoption contexts of other national markets would need to be considered to render findings more generalizable. For applying this study to selected countries in the European Union, the FIFA World Cup could be selected as a sports event of comparative significance. FIFA World Cup or UEFA Euro matches could play a comparative role for some European countries, as the NFL Super Bowl did for the United States; helping some European countries to achieve a 3DTV market saturation of 50\% within a similar timeframe as the American market. This projection is for soccer-enthusiastic and populationwise larger European countries such as Germany, Italy, France, the United Kingdom, and Spain (Matchett, 2013). These five countries do not only share cultural similarities with the United States - but these five countries could probably similar to America also experience a new cycle of 3D cinema from 2022 onwards, kicked off by the Avatar sequels.

\section{FINDINGS AND DISCUSSION}

\section{Colour TV and 3DTV}

In 2012, the NDP Group predicted that by 2019, 200 million 3DTV sets would be sold in the US (CNBC, 2012). This forecast, like most consumer forecasts, obviously failed. Yet, its failure stressed the need for comparatist studies that took lessons learned from earlier adoption patterns into account. As described above, the two most relevant examples in context were HDTV and colour TV. Both were, like 3DTV, additional forms of TV technology. Colour TV and HDTV provided more sophisticated access to TV content, but unlike black and white TV at the time of its introduction, were they not necessary to access TV content. Colour TV was introduced in 1954 and needed 18 years to achieve a market penetration of $50 \%$ by 1972, reaching Rogers' early majority entirely and the mainstream of US society. In 1985, market saturation of $90 \%$ was achieved (Carey \& Elton, 2010). The peak of sales according to the Bass model was reached in 1968, 14 years after market introduction, and after three-quarters of the time period between product launch in 1954 and reaching the critical benchmark of $50 \%$ had passed (Bass, 1969). In 1972, the price for a colour TV set had come down to the equivalent of 1.9 weekly household incomes. Colour TV buyers shared a common problem with HDTV owners and 3DTV purchasers. This problem posed a crucial factor for adoption, according to Rogers. Initially, not enough content existed. Only in 1966 was regular colour TV programming available across the United States (Bebusinessed, 2016).

\section{HDTV \& 3DTV}

When HDTV sets were initially adopted, they suffered from the same crucial problem that Bass had initially laid out, not having enough HDTV content being broadcast. Early adopters helped themselves by watching DVDs of TV shows or Hollywood movies in HD resolution instead (Carey \& Elton, 2010). Another problem that early HDTV introduction suffered was the poor job that TV manufacturers did when putting HDTV sets in public places or using them with SDTV content (Carey \& Elton, 2010). A similar mistake in marketing, an essential factor in the Bass model, would repeat later with 3DTV. Similar to 3DTV, HDTV initially also faced the problem of conflicting technical standards and high prices. Especially the price was 
crucial, according to Rogers, to make a majority adopt (Rogers, 1995). Only after the prices came down to an affordable level, mass adoption took place. Mass adopters also needed to learn new behaviours. Along with the HDTV sets, many consumers were required to understand the remote control's complex handling, did subscriptions for preferred channels and purchased set-top boxes (Baaren et al., 2011). A late majority of adopters would only go through this process once technical bugs had been fixed (Rogers, 1995).

In the learning of new behaviour, another similarity to 3DTV could be seen: while colour TV offered an enhanced experience instead only, compared to black and white TV (Carey \& Elton, 2010). Like for 3DTV, HDTV affected content choices. While sports programming was perceived as a natural fit, soap operas appeared not very appealing. It also affected TV production. While wide angles worked well in HD, close-ups made actors afraid of making their wrinkles and sweat visible (Carey \& Elton, 2010), especially in the porn industry. HDTV introduction began in 1998 (Dupagne \& Driscoll, 2010). From the mid-2000s, mass adoption took place (Carey \& Elton, 2010). A substantial increase happened from 2007 until 2008 when $52 \%$ of homes adopted the new digital technology, and Rogers' critical benchmark was reached. By 2013, 75\% of American households possessed an HDTV set (Grenier-Hemphill, 2015). By 2015, HDTV penetration had reached 81\% of American homes (Fierce Video, 2015). That meant that the mass adoption until reaching the mainstream happened in 10 years only and, therefore, almost twice as fast as the mass adoption of colour TV. In comparison was the adoption of HDTV still slower than black and white TV, which took only eight years (Carey \& Elton, 2010).

\section{DTV Future Prospects and Solution Paths}

The current status of 3DTV was a failure. For changing this status towards mass adoption, 3DTV would need to overcome the abovementioned inhibiting factors. Then, it could reach Rogers' early and late majority. The problem of bringing 3DTV cameras in proximity to the filmed subject, without having unwanted objects covering essential parts of the image, could be approached by using camera drones. Drones flying low could provide a partial solution, filming from a close position above but avoiding unwanted objects. Additional technical solutions could be found for the problems above, as partly indicated. The above solution proposals already addressed the problem of nausea-induction. It could be helpful also, using lesser fast cuts in editing away from one camera angle to another (Postley, 2012). 3D broadcasting of NFL events used only $20 \%$ as much cuts in editing as 2D broadcasting of the same sports events. The stronger immersive environment of a 3DTV experience could make a limited redefinition of Sergej Eisenstein's montage theories for a 3D context useful.

Some scholars recommended a holographic 3DTV system as the only final solution to solve all adverse health effects (Mehrabov, 2015). Again other scholars contradicted and demanded better accommodation to stereoscopic devices' effects (Wang, Tseng, \& Liao, 2015). A strong defender of stereoscopic images supported even their use by billions of people in the form of an exposure "therapy," if possible from childhood onwards (Starks, 2018). Whatever solution would be the appropriate one, both carry at least the possibility of solving the cognitive ability problems successfully. The content was crucial for colour TV and HDTV to reach Rogers' early and late majority. The same goes for 3DTV. 3D programming should also be easy and cheap to be produced to make it commercially viable. While reality TV shows and TV soap operas would production-wise easy to be realized, they would not necessarily be visually interesting enough for 3DTV. 
On the other hand, would Hollywood action blockbusters be visually very appealing (Obrist et al., 2013) but too expensive to be produced. Big live sports events could fill this gap, in which real events were filmed and the recordings transmitted live (Obrist et al., 2013). Sports provided a lot of early 3DTV content (Carey \& Elton, 2010). Sports events also had another benefit. They allowed the viewer to experience emotional bonding when, for example, the own team was playing, thus creating a form of social presence (Shin, 2012). Another scholar perceived real-time conversion from $2 \mathrm{D}$ to $3 \mathrm{D}$ as a method to ensure enough availability of 3DTV programming (Limbachiya, 2014). For an interim period before full 3DTV mass adoption, it would be thinkable to broadcast both a 2D and 3D version of important live events in parallel to minimize commercial risks. The abovementioned poor marketing strategies for 3DTV in the 2010s must be improved to function as part of a successful external communication channel in Bass' adoption model, even if only of secondary importance (Bass, 1969). Also, the product price was a decisive factor for the mass adoption of 3DTV.

Both forerunners, black and white TV and colour TV, reached the mainstream of more than $50 \%$ of American households when the price for a TV set equalled 1.8, respectively 1.9, weekly household incomes (Carey \& Elton, 2010). In 2010, a Philips 42-inch 3DTV set could be purchased for USD 8.999, devices being in the range from USD3,000 to 12,000 (Reagan, 2010). In 2011, a 55-inch 3D LCD HDTV set was available for USD 1,400. Again one year later, the price for a 55-inch device had dropped down to USD 699 in February 2012 (White, 2012). In June 2018, Americans possessed a monthly household income of USD 5,181.25. They were then by more than the factor 3 capable of and ready for 3DTV adoption - a device for USD699 equaling approximately 0.5 weekly household incomes only (Clemons, 2018). When 3DTV was compared to both forerunners colour TV and HDTV, the latter comparison appeared more useful. The mass adoption of HDTV happened only a decade ago, while the one of colour TV took place half a century earlier. HDTV and 3DTV also shared several similarities as mentioned: related to lack of initial content availability, preference of certain (similar) forms of content, effects on production styles, poor initial marketing strategies, dependence on TV set prices, a requirement of adopting new consumer behaviours (Carey \& Elton, 2010). The mass adoption of HDTV was used as a primary temporal pattern to predict future 3DTV adoption. The diffusion speed did not change because of technology, but like half a century before, it was still based on human psychology.

\section{The National Football League (NFL) and 3DTV}

Many of the reasons why the NFL games were consumed in HD, applied to 3D, too: as shown in the previous comparison between HDTV and 3DTV. A comparatist perspective was applied to NFL games in 3DTV, HDTV, and even colour TV. NFL decision-makers also perceived 3D early as a new opportunity. The link between 3D Cinema and 3DTV, between the Avatar movie from 2009 and NFL matches, was traceable. In 2010, the year of the "Avatar effect," a pre-season NFL match between the New York Giants and the New England Patriots was broadcast in 3D by Verizon FiOS for the northeast of the United States (Shanbhag, 2010): the first 3DTV broadcast of an NFL match ever (Shanbhag, 2010). Several NFL matches were produced on an annual basis in 3D, the first NFL football match being broadcasted in 3D live in 2013 (Kim, Kang, Lee, \& Bovik, 2013). Selected NFL matches were screened in 3D multiplexes, and the Super Bowl expanded the popularity of the failed 3DTV sets in the 2010s (Chang et al., 2014). 
Stadium owners were becoming afraid that 3DTV may even take more of the stadium fans away than HDTV already took (Emmons, 2012). This concern was remarkable, as the NFL Super Bowl was the reason why $22 \%$ of people bought an HDTV set (Poor Audiophile, 2013). As a consequence, more people could buy a 3DTV set to watch the NFL Super Bowl. The NFL Super Bowl could become the single most crucial factor sparking 3DTV sales. But before NFL matches could motivate more sales of 3DTV sets, 3DTV was announced dead. The year in which the first 3D live transmission of an NFL match took place was also the year 3DTV was already declared dead (Mehrabov, 2015). 3D is a cyclical technology. The comeback of 3D technology is also expected for TV. The networks offering 3DTV versions of new matches first could gain a competitive advantage compared to other TV networks. Most of the NFL games would need to be available in 3D then, following the HD pattern. Avatar director Cameron embarked in 2020 on a campaign, advocating to make 3D a standard tool in TV production (Pennington, 2020). Successful future 3DTV transmissions of NFL matches would need to be technologically innovative, pending the elimination of adoption inhibiting factors. In the following, 3DTV potential and technical innovations were presented that could impact the 3DTV mass adoption in the 2020s.

Tamir, Wilf, Sabag, Littman, and Birnboim (2013) explicitly stated that 3DTV would provide a more realistic viewing experience for NFL matches because a more realistic rendering of objects would be possible. The shapes even of moving objects and subjects could reliably be predicted from forward or backward video frames. Tamir et al. (2013) assumed that sports events would naturally be the avant-garde of 3D innovations (like once NFL games on early colour TV and first HDTV). Moreover, Tamir et al. (2013) perceived the introduction of 3DTV because of its anticipated impact as more essential and groundbreaking than the launch of the two forerunners, colour TV, and HDTV. This perception can be applied to the abovementioned importance of HDTV. To buy a 3DTV set to watch the Super Bowl could become the single most crucial factor for 3DTV mass adoption in the sense of Rogers' diffusion of innovation model (Rogers, 1995): beating even the past motivation for HDTV set purchases. Companies like Intel continued installing 3D camera systems in NFL stadiums. By 2017, 11 NFL stadiums in the USA were equipped with Intel's 360-degree replay system to offer NFL matches in 3D (LeFebvre, 2017). Intel's 3D cameras provide higher resolution content than before and, therefore, a better viewer experience: recorded with $5 \mathrm{~K}$ ultra-high definition cameras (LeFebvre, 2017).

Another approach supported the perceived meaning of 3DTV. Takeo Kanade's EyeVision 360 system was used for shooting the Super Bowl in 2001 (dos Anjos, Pereira, \& Gaspar, 2018). The many cameras placed in the stadium allowed to render smooth transitions between different viewpoints. With the technology of today, viewers would be able to choose their preferred view, even if it would be directly behind one of the players (dos Anjos et al., 2018). Due to object tracking, extraction, and separation using calibrated cameras, this viewpoint technology functioned in real-time, making it useful for immersive 3DTV live events (Sabirin, Yao, Nonaka, Sankoh, \& Naito, 2018). With such technical options, appealing to consumer needs, NFL TV transmissions would meet several adoption criteria as defined by Rogers (Rogers, 1995).

Avatar sequels in cinema could initiate the 3DTV mass adoption fueled by NFL TV transmissions. James Cameron's Avatar initially kicked off a recent cycle of 3D in cinema, followed by the failed 3DTV trend of the 2010s (Napoli, 2018). But for the 2020s, four Avatar 
sequels had been announced. Avatar 2 was scheduled for cinema release on December 18, 2021, to be followed by other sequels until Avatar 5 would be released on December 19, 2027. Director Cameron, one of the most successful Hollywood movie directors ever, promised an outstanding 3D experience with "revolutionary" 3D projection technology and higher detail levels (Busch, 2020). The launch of the Avatar sequels could establish a primary temporal diffusion pattern for 3DTV. Cinema could lead, and TV could follow from 2022 onwards. Full mass adoption of 3DTV could be reached by 2032 when applying the temporal scope of the decade-long HDTV diffusion to 3DTV from 2022 onwards. At least $50 \%$ of all American households would by 2032 possess a 3DTV set if the abovementioned inhibiting factors could be successfully addressed. The S-curve peak of Bass' model would be achieved after three-quarters of the time from pending 3DTV re-introduction until reaching the critical benchmark of 50\% would have passed, around 2029/2030 (Bass, 1969). This mass adoption would mainly take place due to internal influence. After this point in time, mass adoption would slow down but still reach the American mainstream (Bass, 1969). Also, a secondary temporal diffusion pattern of lesser probability would be possible. If the 3DTV diffusion would follow the slower pattern of colour TV, it could take 18 years until 2040 to reach Rogers' early and late majority (Rogers, 1995). Bass' S-curve peak would then be reached by 2035/36 (Bass, 1969).

If the Avatar 2 release date were rescheduled again, the temporal pattern would have a latter starting point. 3DTV sceptics should remember that even black and white TV had false starts before World War II before it finally took off after the War (Carey \& Elton, 2010). 3DTV mass adoption would be in good company. NFL games could be the key events providing the right content to support 3DTV mass adoption reaching the US mainstream until 2032 (primary diffusion pattern) or 2040 (secondary diffusion pattern) according to the Bass model (Bass, 1969). The researcher's assumption was based on the earlier, demonstrated (limited) effect of NFL matches kicking off a fad of 3DTV in the 2010s. The researcher's hypothesis was further taking the earlier, demonstrated link between HDTV set purchases and NFL matches, and the projection from HDTV onto 3DTV into account. If all inhibiting factors to adoption can be eliminated, technologically innovated NFL TV transmissions in the 2020s could kick off the mass adoption of 3DTV in the United States. NFL games could represent the TV component, following up on the Avatar sequels' lead in cinema to come.

\section{CONCLUSION}

Overall, the comparatist perspective proved to be very useful. It helped to avoid the errorprone approaches of many other consumer forecasts, which were mostly wrong (Emmer, 2018). It also associated technological with sociological factors to study mass adoption, using a crucial but neglected study approach. Mass adoption of 3DTV, sparked off by Avatar sequels in cinema and kicked off by NFL game transmissions on TV, appeared likely to happen. If the Avatar sequels would be released from late 2021 onwards, bringing 3D cinema back on a big scale, NFL TV transmissions could kick off another cycle of 3DTV as perhaps the single most crucial factor. Super Bowl matches would probably function as the most important NFL TV events, helping to spark 3DTV mass adoption. Following the primary temporal diffusion pattern based on Bass' model, 50\% of Americans could possess 3DTV sets by 2032. Following the secondary temporal diffusion pattern based on Bass' model, $50 \%$ of Americans could have 3DTV sets by 2040 . 
For a market saturation of 50\% to happen until either 2032 or 2040, different criteria would need to be met. Future 3DTV sets would ideally need to use HDR displays, 4K resolution, binaural audio, and complete 3D packet transmission in video streaming. Video cameras recording NFL sports matches would need to be very close to the playing field. Colour match and alignment between the two lenses of a 3D camera would need to be improved to reduce nausea-inducing effects in viewers. All 3DTV sets to be manufactured in the future should be non-stereoscopic devices - to comfort the consumer's adoption ability. Much more sports content as of 2020, and ideally, most of all NFL TV content, should be offered in a 3D version. Marketing strategies for 3DTV sets would need to be improved in terms of timing, product demonstrations, offering integrated solutions. The prices of future 3DTV sets would need to remain below or equal to 1.9 weekly household incomes.

\section{REFERENCES}

Baaren, E., van de Wijngaert, L., \& Huizer, E. (2011). Understanding technology adoption through individual and context characteristics: The case of HDTV. Journal of Broadcasting E Electronic Media 55(1), 72-89. doi: 10.1080/08838151.2011.546257

Bass, F. M. (1969). A new product growth for model consumer durables. Management Science 15(5), 215-227. doi: 10.1287/mnsc.15.5.215

Bass, F. M., Krishnan, T. V., \& Jain, D. C. (1994). Why the Bass model fits without decision variables. Marketing Science 13(3), 203-223. doi: 10.1287/mksc.13.3.203

Bebusinessed (2016). History of the television. Bebusinessed. Retrieved https://bebusinessed. com/history/history-of-the-television

Britannica (2020). The development of sports programming. Retrieved from https://www. britannica.com/art/television-in-the-United-States/M-A-S-H\#ref283629

Busch, H. (2020, January). Alles zu Avatar 2, 3, 4 und 5: Die nächste Kinorevolution steht vor der Tür [All about Avatar 2, 3, 4 and 5: The next cinema revolution is coming]. Moviepilot. Retrieved from https://www.moviepilot.de/news/alles-zu-avatar-2-3-4-und-5-dienachste-kinorevolution-steht-vor-der-tur-199815

Carey, J. \& Elton, M. C. (2010). When media are new: Understanding the dynamics of new media adoption and use. Ann Arbor: University of Michigan Press.

Carroll, B. (2020, October). Super Bowl. American Football. Britannica. Retrieved from https:// www.britannica.com/sports/Super-Bowl

Chang, J., Jung, K., Kim, W., Moon, S. K., Freivalds, A., Simpson, T. W., \& Baik, S. P. (2014). Effects of weight balance on a 3D TV shutter type glasses: Subjective discomfort and physical contact load on the nose. International Journal of Industrial Ergonomics, 44(6), 801-809. doi: 10.1016/j.ergon.2014.10

Chen, C., Wang, J., Lu, X., Liu, Y., \& Chen, X. (2018). Assessment of 3DTV-related fatigue with resting-state fMRI. Signal Processing: Image Communication, 64, 99-106. doi: 10.1016/j. image.2018.02.015

Clemons, T. (2018, June). Best 3D TVs. Lifewire. Retrieved from https://www.lifewire.com/ best-3d-tvs-1847765

CNBC (2012). The International 3D Society E 3D@Home Consortium release 2012-2013 3D forecast and trends. Retrieved from https://www.cnbc.com/id/100134090 
Dibra, M. (2015). Rogers theory on diffusion of innovation - the most appropriate theoretical model in the study of factors influencing the integration of sustainability in tourism businesses. Procedia: Social and Behavioral Sciences 195, 1453-1462. doi: 10.1016/j. sbspro.2015.06.443

dos Anjos, R. K., Pereira, J., \& Gaspar, J. (2018). A navigation paradigm driven classification for video-based rendering techniques. Computers \& Graphics, 77, 205-216. doi: 10.1145/1944745.1944776.910

Dupagne, M., \& Driscoll, P. D. (2010). Comparison between early high-definition television owners and non-owners. Journal of Media Economics, 23(4), 216-230. doi: $10.1080 / 08997764.2010 .527226$

Emmer (2018, July). 95 percent of new products fail. Here are 6 steps to make sure yours don't. Inc. Retrieved from https://www.inc.com/marc-emmer/95-percent-of-newproducts-fail-here-are-6-steps-to-make-sure-yours-dont.html

Emmons, B. (2012). Interview with Kathleen Hessert, founder and president of Buzz Mgr and SportsMediaChallenge. International Journal of Sport Communication, 5(4), 454-456. doi: 10.1123/ijsc.5.4.454

Fan, Z. P., Che, Y. J., \& Chen, Z. Y. (2017). Product sales forecasting using online reviews and historical sales data: A method combining the Bass model and sentiment analysis. Journal of Business Research, 74, 90-100. doi: 10.1016/j.jbusres.2017.01.010

Fierce Video (2015). HDTV penetration reaches $81 \%$ of U.S. homes. Retrieved from https:// www.fiercevideo.com/cable/hdtv-penetration-reaches-81-u-s-homes

Fleming-May, R. A., \& Green, H. (2016). Digital innovations in poetry: Practices of creative writing faculty in online literary publishing. Journal of the Association for Information Science and Technology, 67(4), 859-873. doi: 10.1002/asi.23428

Franceschinis, C., Thiene, M., Scarpa, R., Rose, J., Moretto, M., \& Cavalli, R. (2017). Adoption of renewable heating systems: An empirical test of the diffusion of innovation theory. Energy, 125, 313-326. doi: 10.1016/j.energy.2017.02.060

Grenier-Hemphill, R. (2015). Declining attendance trends in collegiate and professional sports. Corvallis: University of Oregon Press.

Gunkel, B. (2014, February). 14,000 TV channels worldwide. Playbox Technology. Retrieved from https://playboxtechnology.com/newsroom/f/14000-tv-channels-worldwide

Katzmeier, D. (2017, January). Shambling corpse of 3D TV finally falls down dead. CNET. Retrieved from https:// https://www.cnet.com/news/shambling-corpse-of-3d-tvfinally-falls-down-dead

Kellnhofer, P., Didyk, P., Wang, S. P., Sitthi-Amorn, P., Freeman, W., Durand, F., \& Matusik, W. (2017). 3DTV at home: eulerian-lagrangian stereo-to-multiview conversion. ACM Transactions on Graphics, 36(4), 1-13. doi: 10.1145/3072959.3073617

Kim, S., \& Jeon, T. (2016). Seamless video switching system for service compatible 3DTV broadcasting. ETRI Journal, 38(5), 847-857. doi: 10.4218/etrij.16.2615.0036

Kim, T., Kang, J., Lee, S., \& Bovik, A. C. (2013). Multimodal interactive continuous scoring of subjective $3 \mathrm{D}$ video quality of experience. IEEE Transactions on Multimedia, 16(2), 387402. doi: 10.1109/TMM.2013.2292592 
Koonce Jr, G.E. (2013). Role transition of National Football League retired athletes: A grounded theory approach in Marquette Sports Law Review (Doctoral dissertation). Retrieved from ProQuest Dissertations \& Theses Global database (3506011).

Krishnan, S., \& Lymm, J. (2016). Determinants of virtual social networks diffusion: Insights from cross-country data. Computers in Human Behavior, 54, 691-700. doi: 10.1016/j. chb.2015.07.055

Lechner, B. J. (1999). The dawn of terrestrial digital television broadcasting in the United States. SID Symposium Digest of Technical Papers 30(1), 104-107. doi: 10.1889/1.1833947

LeFebvre, R. (2017, September). Intel installed its 3D camera system in eight more NFL stadiums. Engadget. Retrieved from https://www.engadget.com/2017-09-07-intelinstalled-3d-camera-system-eight-more-nfl-stadiums.html

Leswing, K. (2017, January). 3D TV is dead. Business Insider. Retrieved from https://www. businessinsider.com/3d-tv-is-dead-2017-1

Limbachiya, A. M. (2014). 2D to 3D video conversion. International Journal for Research in Applied Science \& Engineering Technology 12(2), 233-239. doi: 10.3390/app10041275

Luque, F. P., Galloso, I., Feijoo, C., Martín, C. A., \& Cisneros, G. (2014). Integration of multisensorial stimuli and multimodal interaction in a hybrid 3DTV system. ACM Transactions on Multimedia Computing, Communications, and Applications, 11(1), 1-22. doi: $10.1145 / 2617992$

LyngSat (2014).3D. Retrieved from https://web.archive.org/web/20140604173259/http:// www.lyngsat.com/3d/index.html

Macedonia, M. (2007). The future arrives... finally. Computer 40(2), 101-103. doi: 10.1109/ MC.2007.75

Matchett, K. (2013, March). Power ranking the 25 best soccer nations based on per capita. Bleacher Report. Retrieved from https://bleacherreport.com/articles/1573794-powerranking-the-25-best-soccer-nations-based-on-per-capita

Mehrabov, I. (2015). Novel televisual environments. Immersive spectatorship and the future of stereoscopic 3DTV. Journal of European Television History E Culture 4(7), 99-109. doi: 10.18146/2213-0969.2015.jethc084

Napoli, P. M. (Ed.) (2018). Mediated communication. Berlin/Boston: Walter de Gruyter.

Nielsen (2017). Super Bowl LI draws 111.3 million TV viewers, 190.8 million social media interactions.Nielsen. Retrieved from https://www.nielsen.com/us/en/insights/ article/2017/super-bowl-li-draws-111-3-million-tv-viewers-190-8-million-socialmedia-interactions/

Obrist, M., Wurhofer, D., Meneweger, T., Grill, T., \& Tscheligi, M. (2013). Viewing experience of 3DTV: An exploration of the feeling of sickness and presence in a shopping mall. Entertainment computing 4(1), 71-81. doi: 10.1016/j.entcom.2012.03.001

Paul, M. (2016). Efficient multi-view video coding using 3D motion estimation and virtual frame. Neurocomputing, 175, 544-554. doi: 10.1016/j.neucom.2015.10.094

Pennington, A. (2020, May). Behind the Scenes: Avatar 2 and 3. IBC. Retrieved from https:// www.ibc.org/trends/behind-the-scenes-avatar-2-and-3/6007.article

Pilot Navigating Broadcasting's Future (2020). First HDR/WCG ecosystem established. Retrieved from https://nabpilot.org/first-hdrwcg-television-ecosystem-established-2/ 
Poor Audiophile (2013). Over 20\% of people bought a new HDTV to watch the Superbowl. Retrieved from https://www.pooraudiophile.com/2013/02/over-20-of-people-bought-newhdtv-to.html.

Postley, H. (2012). Sports: 3D TV's toughest challenge. IEEE Spectrum 49(11), 40-44. doi: 10.1109/MSPEC.2012.6341203

Reagan, G. (2010, January). How much will a 3D TV cost you? Business Insider. Retrieved from https://www.businessinsider.com/how-much-will-a-3d-tv-cost-you-2010-1

Rogers, E. M. (1995). Diffusion of innovations. New York: Free Press.

Sabirin, H., Yao, Q., Nonaka, K., Sankoh, H., \& Naito, S. (2018). Toward real-time delivery of immersive sports content. IEEE MultiMedia, 25(2), 61-70. doi: 10.1109/ MMUL.2018.112142739

Sanderson, A. R., \& Siegfried, J. J. (2018). The role of broadcasting in national collegiate athletic association sports. Review of Industrial Organization, 52(2), 305-321. doi: 10.1007/ s11151-017-9593-9

Shanbhag, R. (2010, August). Verizon FiOS to broadcast NFL game in 3D. Sports Techy. Retrieved from http://sports.tmcnet.com/broadcasting/articles/95033-verizonfios-broadcast-nfl-game-3d.htm

She, Z. Y., Cao, R., Xie, B. C., Ma, J. J., \& Lan, S. (2019). An analysis of the wind power development factors by generalized Bass Model: A case study of China's eight bases. Journal of cleaner production, 231, 1503-1514. doi: 10.1016/j.jclepro.2019.05.255

Shin, D. H. (2012): 3DTV as a social platform for communication and interaction. Information Technology \& People 25(1), 55-80. doi: 10.1108/09593841211204344

Silva, R. (2019, November). 3D TV dies: Is it really the end? Lifewire. Retrieved from https:// www.lifewire.com/why-3d-tv-died-4126776

Starks, M. (2018). 3DTV and 3D movie technology. Las Vegas: Stereoscopic Press.

Tamir, M., Wilf, I., Sabag, S., Littman, R., \& Birnboim, M. (2013, October). Method and system for creating three-dimensional viewable video from a single video stream. United States Patent Application Publication. Retrieved from https://patentimages.storage. googleapis.com/34/1d/32/fad07587763d67/US20130278727A1.pdf

Vatolin, D. (2011, December). Understanding requirements for high-quality 3D video: A test in stereo perception. 3D Roundabout. Retrieved from http://3droundabout. com/2011/12/5788/understanding-requirements-for-high-quality-3d-video-atest-in-stereo-perception.html

Wang, H. M., Tseng, H. C., \& Liao, K. Y. (2015). Comfortable disparity modification for existing DIBR systems. Journal of Information Science and Engineering, 31(5), 1577-1592. doi: 10.6688/JISE.2015.31.5.5

Wasko, J. (2009). A companion to television. Malden: Blackwell Publishing.

Wenner, L. (1989): Media, sports \& society. Newbury Park: Sage Publications.

White, M. C. (2012, March). Hope you didn't buy a 3D TV last year. Time. Retrieved from http://business.time.com/2012/03/22/hope-you-didnt-buy-a-3d-tv-last-year Wiki (2012). 3D TV. Wiki Retrieved from http://wiki.csisdmz.ul.ie/wiki/3D_TV 
Wolf, A. (2010, May). TWICE 3D 2010 panel: In-store demos will drive 3D sales. Twice. Retrieved from https://www.twice.com/news/twice-3d-2010-panel-store-demoswill-drive-3d-sales-17071 